\title{
Entrelacs
}

Cinéma et audiovisuel

HS | 2012

Le post-humain et les enjeux du sujet

\section{« Devenir-machine » et post-organique : une lecture d'Orlan et de Cronenberg}

Jacques Brunet-Georget

\section{(2) OpenEdition}

Journals

Édition électronique

URL : http://journals.openedition.org/entrelacs/309

DOI : 10.4000/entrelacs.309

ISSN : 2261-5482

Éditeur

Éditions Téraèdre

Édition imprimée

Date de publication : 2 février 2012

ISBN : 978-2296567177

ISSN : 1266-7188

\section{Référence électronique}

Jacques Brunet-Georget, « « Devenir-machine » et post-organique : une lecture d'Orlan et de

Cronenberg », Entrelacs [En ligne], HS | 2012, mis en ligne le 01 août 2012, consulté le 20 avril 2019

URL : http://journals.openedition.org/entrelacs/309 ; DOI : 10.4000/entrelacs.309

Ce document a été généré automatiquement le 20 avril 2019.

Tous droits réservés 


\title{
«Devenir-machine » et post-organique: une lecture d'Orlan et de Cronenberg
}

\author{
Jacques Brunet-Georget
}

1 Le texte complet de cet article est publié dans l'ouvrage :

Post humain et les enjeux du sujet

Editeur : L'HARMATTAN (2 février 2012)

Collection Ouverture Philosophique

ISBN-10 : 2296567177

ISBN-13 : 978-2296567177

\section{RÉSUMÉS}

Depuis quelques années, l'art met en scène le corps vivant - souffrant et jouissant - d'une manière que certains qualifient de «post-organique»: ses dispositifs contribuent à modifier l'intelligibilité du sujet dit « humain », notamment à travers les nouvelles porosités entre le corps et la machine. En s'appuyant sur deux démarches contemporaines, celle d'ORLAN, qui soumet son propre visage, dans des opérations-performances, à des interventions de chirurgie plastique, et celle de David Cronenberg, qui interroge, dans le film Crash, l'avènement d'une post-sexualité fondée sur la compatibilité de la chair et du métal, il s'agirait de montrer comment le « devenirmachine " du corps affecte le sujet comme entité autonome et de dégager les équivoques possibles de ce processus : le dépassement du concept de corps humain ramène-t-il l'être à la pure et simple dissémination de ses traits ou laisse-t-il entrevoir la possibilité de produire une certaine forme de transcendance, non symbolique et non figurable? 


\section{AUTEUR}

\section{JACQUES BRUNET-GEORGET}

Chargé de cours en Philosophie à l'Université Bordeaux III et doctorant au sein du laboratoire LNS ("Lumières, Nature, Sociétés"), Jacques Brunet-Georget achève une thèse portant sur les modifications du statut et des usages du corps dans le champ contemporain, tout particulièrement dans les pratiques artistiques (cinéma, littérature et performances corporelles) et dans un dialogue critique avec la théorie psychanalytique 